\title{
Penerapan Metode Profile Matching pada Pemilihan Guru Terbaik SMK Madani
}

\author{
Susliansyah ${ }^{1}$, Annisa Dwi Wijayanti' ${ }^{2}$, Heny Sumarno ${ }^{3}$, Hendro Priyono ${ }^{4}$, Linda Maulida ${ }^{4}$ \\ Sistem Informasi, STMIK Nusa Mandiri \\ Sistem Informasi, Universitas Bina Sarana Informatika \\ Jl. Kamal Raya No. 18, Ringroad Barat, Cengkareng, Jakarta Barat \\ 021-54376398 \\ susliansyah.slx@bsi.ac.id, annisadwiwijayanti12@gmail.com, heny_nyno@yahoo.com, \\ hendrop250@gmail.com,linda.lma@bsi.ac.id
}

\begin{abstract}
Depok Madani Vocational School is a Vocational High School consisting of 2 majors namely Light Vehicle Engineering (TKR) and Computer and Network Engineering (TKJ) with 20 teachers as instructors from class X to class XII. The selection of the best teachers is done once a month to motivate the teacher in conducting teaching and learning activities. Schools in making decisions are often influenced by subjectivity and are done manually. Resulting in social jealousy among teachers and inaccurate decision results. Therefore, in assessing the best teachers a decision support system is needed in order to obtain accurate results. Decision Support System methods used in this study is Profile Matching. The method determines the value of weights on each criterion, which is to be present on time, responsibility, dress neatly and politely, participate and contribute, be active and productive, and help fellow teachers, which is followed by a ranking process. The result of the comparison of the two methods above is to produce the same chosen alternative, so that both methods can be applied to help the school's decision making.
\end{abstract}

Keywords: Decision Support System, Profile Matching, Selection of the Best Teachers

\begin{abstract}
Abstrak
SMK Madani Depok adalah Sekolah Menengah Kejuruan yang terdiri dari 2 penjurusan yaitu Teknik Kendaraan Ringan (TKR) dan Teknik Komputer dan Jaringan (TKJ) dengan 20 guru sebagai pengajar dari kelas X sampai kelas XII. Pemilihan guru terbaik dilakukan sebulan sekali guna memotivasi guru dalam melakukan kegiatan belajar mengajar. Pihak sekolah dalam mengambil keputusan sering dipengaruhi faktor subjektifitas dan dilakukan secara manual. Sehingga menyebabkan kecemburuan sosial dikalangan guru dan ketidakakuratan hasil keputusan. Oleh karena itu dalam menilai guru terbaik diperlukan sistem penunjang keputusan agar didapatkan hasil yang akurat. Metode Sistem Penunjang Keputusan yang dipergunakan dalam penelitian ini Profile Matching. Metode tersebut menentukan nilai bobot pada setiap kriteria, yaitu hadir tepat waktu, tanggung jawab, berpakaian rapih dan sopan, berpartisipasi dan berkontribusi, aktif dan produktif, dan membantu rekan guru, yang dilanjutkan dengan proses perangkingan. Hasil komparasi dari kedua metode diatas adalah menghasilkan alternatif terpilih yang sama, sehingga kedua metode tersebut dapat diterapkan untuk membantu pengambilan keputusan pihak sekolah.
\end{abstract}

Kata kunci: Sistem Penunjang Keputusan, Profile Matching, Pemilihan Guru Terbaik

\section{PENDAHULUAN}

Eksistensi guru harus dijaga karena merupakan bagian terpenting dari berkembangnya kualitas suatu sekolah. Bentuk apresiasi sekolah kepada guru merupakan salah satu upaya dalam memberikan penghargaan atas kinerja pendidik dalam memberikan kualitas mengajar terbaik bagi para 
murid. Pemilihan guru terbaik dilakukan sebulan sekali guna memotivasi guru dengan cara pemberian hadiah. Dari proses penilaian guru tersebut permasalahan yang sering muncul yaitu ketidaktepatan pihak sekolah dalam memberikan penilaian terhadap guru karena dipengaruhi faktor subjektifitas dan dilakukan secara manual. Sehingga pengambilan keputusan secara subjektif belum bisa mendefinisikan dengan baik dalam penilaian kinerja guru yang menimbulkan kecemburuan sosial.

Berdasarkan permasalahan diatas untuk menghindari subyektifitas keputusan yang dihasilkan diperlukan suatu sistem pendukung keputusan (SPK) yang dapat membantu menilai kinerja guru dalam memutuskan menjadi seorang guru yang terbaik. SPK merupakan suatu sistem menggunakan model yang dibangun untuk membantu menyelesaikan masalah-masalah semi terstruktur [1]. Metode Profile Matching dapat mencari karyawan terbaik dari kriteria-kriteria yang telah ditentukan. Metode ini dipilih karena mampu menyeleksi alternatif terbaik dari sejumlah alternatif, dalam hal ini alternatif yang dimaksudkan yaitu yang layak menjadi karyawan terbaik [2]. Untuk menganalis karyawan berprestasi yang sesuai dengan kinerja tertentu dilakukan dengan metode Profile Matching, dimana dalam proses ini terlebih dahulu kita tentukan aspek atau kriteria yang menjadi landasan dalam perhitungan kandidat karyawan berprestasi. Karyawan mana yang memenuhi kriteria adalah dimana hasil point kerja harus memenuhi syarat wajib, dan syarat tersebut adalah hasil point harus 5, point tersebut dapat dilihat melalui hasil kinerjanya selama bekerja di perusahaan tersebut [3]. Profile Matching akan membantu dalam mekanisme perhitungan untuk mengambil keputusan terhadap suatu objek yang akan dinilai dilihat dari tingkat variabel prediktor yang ideal yang harus dimiliki oleh calon karyawan tetap [4]. Profile Matching adalah sebuah mekanisme pengambilan keputusan dengan mengasumsikan bahwa terdapat tingkat variabel prediktor yang ideal yang harus dimiliki oleh pelamar, bukannya tingkat minimal yang harus dipenuhi atau dilewati [5].

\section{METODOLOGI PENELITIAN}

\subsection{Pengumpulan Data}

Dalam penelitian ini metode yang digunakan dalam pengumpulan data sebagai berikut:

a Observasi

Melakukan pengamatan langsung di SMK Madani Depok terhadap alur penentuan guru berprestasi.

b Wawancara

Melakukan tanya jawab dengan Kepala SMK Madani Depok untuk mengetahui alur dari guru berprestasi.

\subsection{Keputusan}

Keputusan merupakan hasil dari proses memilih pilihan terbaik diantara beberapa alternatif yang telah tersedia. Pada proses pengambilan 
keputusan, kita akan berusaha mencurahkan segala pemikiran dan melakukan kegiatan yang diperlukan untuk mendapatkan pilihan yang terbaik. Kegiatan yang diperlukan adalah mengumpulkan data dan informasi yang diperlukan serta menentukan metode pengambilan keputusan yang akan digunakan sebagai dasar untuk mengambil keputusan [6].

\subsection{Sistem Pendukung Keputusan}

Sistem Pendukung Keputusan (SPK) adalah suatu informasi berbasis komputer yang menghasilkan berbagai alternatif keputusan untuk membantu manajemen dalam menangani berbagai permasalahan yang terstruktur ataupun tidak terstruktur dengan menggunakan data dan model [7]. Sistem Penunjang Keputusan adalah suatu sistem informasi spesifik yang ditunjukan untuk membantu manajemen dalam mengambil keputusan yang berkaitan dengan persoalan yang bersifat semi terstruktur. Sistem ini memiliki fasilitas untuk menghasilkan berbagai alternatif yang digunakan oleh pemakai [7].

\subsection{Profile Matching}

Profile Matching akan membantu dalam mekanisme perhitungan untuk mengambil keputusan terhadap suatu objek yang akan dinilai dilihat dari tingkat variabel prediktor yang ideal yang harus dimiliki oleh calon karyawan tetap[4]. Adapun algoritma penyelesaian metode profile matching terdapat 2(dua) konsep sebagai berikut [7]:

Konsep I:

a. Langkah 1 : Mendefinisikan terlebih dahulu kriteria-kriteria yang akan di jadikan sebagai tolak ukur penyelesaian masalah.

b. Langkah 2 : Menghitung Nilai GAP antara profile subjek dengan profile yang dibutuhkan.

c. Langkah 3 : Menghitung Nilai Mapping GAP yang bersumber dari analisis GAP

d. Langkah 4 : Menghitung Nilah akhir

e. Langkah 5 : Melakukan Perangkingan

Konsep II:

a. Langkah 1 : Mendefinisikan terlebih dahulu kriteria-kriteria yang akan di jadikan sebagai tolak ukur penyelesaian masalah dan menentukan skala prioritas dari masing-masing kriteria (profil kriteria).

b. Langkah 2 : Menghitung Nilai GAP dan Mapping GAP

c. Langkah 3 : Menghitung nilai Rata-Rata Core Factor dan Nilai Rata Secondary Factor. Adapun rumus menghitung nilai rata-rata Core Factor dan Secondary Factor sebagai berikut:

$$
N C F=\frac{\sum N C}{\sum I C}
$$


$N S F=\frac{\sum N S}{\sum I S}$

Dimana :

NCF : Nilai Rata-rata Core Factor

NSF : Nilai Rata-rata Secondary Factor

NC : Jumlah Total Nilai Core Factor

IC : Jumlah Total Nilai Item Core Factor

NS : Jumlah Total Nilai Secondary Factor

IS : Jumlah Total Nilai Item Secondary Factor

d. Langkah 4 : Melakukan perangkingan

\subsection{Guru}

Menurut (Sumardi, 2016) menyimpulkan bahwa "Guru merupakan tenaga kependidikan yang dituntut memiliki tingkat kemahiran dan keahlian yang memadai untuk melaksanakan tugas membimbing, mengajar, dan mendidik peserta didik agar mampu mengembangkan potensi yang dimiliki peserta didik itu secara optimal".

\section{HASIL DAN PEMBAHASAN}

\subsection{Analisa Data}

Pada analisis data dalam menggunakan metode Simple Additive Weighting (SAW) dan metode Profile Matching dilakukan klasifikasi pembobotan disetiap kriterianya. Dimana dalam pemilihan guru terbaik ini, diperoleh kriteria-kriteria dan pembobotannya. Kriteria yang digunakan sebagai penilaian adalah sebagai berikut:

Tabel 1. Kriteria

\begin{tabular}{|c|c|}
\hline No & Kriteria \\
\hline 1 & Hadir tepat waktu \\
\hline 2 & Tanggung jawab \\
\hline 3 & Berpakaian rapih dan sopan \\
\hline 4 & Berpartisipasi dan berkontribusi \\
\hline 5 & Aktif dan produktif \\
\hline 6 & Membantu rekan guru \\
\hline
\end{tabular}

Sample alternatif yang digunaan dalam penelitian ini adalah 20 guru di SMK Madani Depok, yaitu:

Tabel 2. Data Guru

\begin{tabular}{|c|l|c|}
\hline No & \multicolumn{1}{|c|}{ Nama Guru } & Alternatif (Nama Guru) \\
\hline 1 & Abdul Odih & A1 \\
\hline 2 & Adhimas Cahyo Kuncoro & A2 \\
\hline
\end{tabular}




\begin{tabular}{|c|l|c|}
\hline No & \multicolumn{1}{|c|}{ Nama Guru } & Alternatif (Nama Guru) \\
\hline 3 & Agus Darsono & A3 \\
\hline 4 & Bias Fajar Baskoro & A4 \\
\hline 5 & Budi Kriswana & A5 \\
\hline 6 & Dedy Heryadi & A6 \\
\hline 7 & Devi Tresna Senjaya & A7 \\
\hline 8 & Dian Eko & A8 \\
\hline 9 & Fatmawati & A9 \\
\hline 10 & H. Didih Suwardi & A10 \\
\hline \multicolumn{2}{|c|}{ Sumber : SMK Madani Depok } \\
\hline
\end{tabular}

Mendefinisikan terlebih dahulu kriteria-kriteria yang akan di jadikan sebagai tolak ukur penyelesaian masalah dan menentukan skala prioritas dari masing-masing kriteria (profil kriteria). Berikut adalah aspek-aspek yang digunakan untuk pemilihan guru terbaik:

Tabel 3. Keterangan Aspek kriteria

\begin{tabular}{|l|l|}
\hline \multicolumn{1}{|c|}{ Aspek } & \multicolumn{1}{c|}{ Kriteria } \\
\hline Aspek Disiplin & D1 : Hadir tepat waktu \\
& D2 : Tanggung jawab dalam bekerja \\
& D3 : Berpakaian Rapih dan sopan \\
\hline Aspek Kerjasama & K1 : Berpartisipasi dan berkontribusi \\
& K2 : Aktif dan produktif \\
& K3 : Membantu rekan guru \\
\hline
\end{tabular}

Dimana nilai aspek sub kriterianya adalah sebagai berikut:

Tabel 4. Skala Penilaian

\begin{tabular}{|c|c|}
\hline Nilai & Keterangan \\
\hline 1 & Sangat Kurang \\
\hline 2 & Kurang \\
\hline 3 & Cukup \\
\hline 4 & Tinggi \\
\hline 5 & Sangat Tinggi \\
\hline
\end{tabular}

\subsection{Menghitung Nilai GAP dan Mapping GAP}

a. Perhitungan pemetaan gap kompetensi akan dipaparkan untuk tiap aspeknya, adapun aspek-aspeknya yaitu meliputi:

Tabel 5. Aspek Disiplin untuk Pengelompokan GAP

\begin{tabular}{|c|l|c|c|c|c|}
\hline \multirow{2}{*}{ No } & \multicolumn{2}{|c|}{ Nama } & \multicolumn{3}{|c|}{ Aspek Kedisiplinan } \\
\cline { 3 - 5 } & & D1 & D2 & D3 & \\
\hline 1 & Abdul Odih & 5 & 5 & 5 & \\
\hline 2 & Adhimas Cahyo Kuncoro & 5 & 5 & 4 & \\
\hline
\end{tabular}




\begin{tabular}{|c|l|c|c|c|c|}
\hline \multirow{2}{*}{ No } & \multicolumn{1}{|c|}{ Nama } & \multicolumn{3}{|c|}{ Aspek Kedisiplinan } \\
\cline { 3 - 5 } & & D1 & D2 & D3 & \\
\hline 3 & Agus Darsono & 5 & 5 & 5 \\
\hline 4 & Bias Fajar Baskoro & 5 & 5 & 4 \\
\hline 5 & Budi Kriswana & 5 & 5 & 5 \\
\hline 6 & Dedy Heryadi & 5 & 4 & 5 \\
\hline 7 & Devi Tresna Senjaya & 5 & 5 & 4 \\
\hline 8 & Dian Eko & 4 & 4 & 5 \\
\hline 9 & Fatmawati & 5 & 5 & 4 \\
\hline 10 & H. Didih Suwardi & 5 & 5 & 5 \\
\hline & Profil Ideal & $\mathbf{5}$ & $\mathbf{5}$ & $\mathbf{5}$ & \\
\hline 1 & Abdul Odih & 0 & 0 & 0 & GAP \\
\hline 2 & Adhimas Cahyo Kuncoro & 0 & 0 & -1 \\
\hline 3 & Agus Darsono & 0 & 0 & 0 \\
\hline 4 & Bias Fajar Baskoro & 0 & 0 & -1 \\
\hline 5 & Budi Kriswana & 0 & 0 & 0 \\
\hline 6 & Dedy Heryadi & 0 & -1 & 0 \\
\hline 7 & Devi Tresna Senjaya & 0 & 0 & -1 \\
\hline 8 & Dian Eko & -1 & -1 & 0 \\
\hline 9 & Fatmawati & 0 & 0 & -1 \\
\hline 10 & H. Didih Suwardi & 0 & 0 & 0 \\
\hline
\end{tabular}

Tabel 6. Aspek Kerjasama untuk pengelompokan GAP

\begin{tabular}{|c|l|c|c|c|c|}
\hline \multirow{2}{*}{ No } & \multicolumn{1}{|c|}{ Nama } & \multicolumn{3}{|c|}{ Aspek Kerjasama } \\
\cline { 3 - 5 } & & K1 & K2 & K3 & \\
\hline 1 & Abdul Odih & 4 & 4 & 4 \\
\hline 2 & Adhimas Cahyo Kuncoro & 5 & 4 & 5 \\
\hline 3 & Agus Darsono & 4 & 4 & 4 \\
\hline 4 & Bias Fajar Baskoro & 4 & 5 & 4 \\
\hline 5 & Budi Kriswana & 4 & 5 & 4 \\
\hline 6 & Dedy Heryadi & 4 & 4 & 4 \\
\hline 7 & Devi Tresna Senjaya & 5 & 4 & 4 \\
\hline 8 & Dian Eko & 4 & 4 & 4 \\
\hline 9 & Fatmawati & 4 & 4 & 4 \\
\hline 10 & H. Didih Suwardi & 4 & 4 & 4 & \\
\hline & Profil Ideal & $\mathbf{5}$ & $\mathbf{5}$ & $\mathbf{5}$ & \\
\hline 1 & Abdul Odih & -1 & -1 & -1 & GAP \\
\hline 2 & Adhimas Cahyo Kuncoro & 0 & -1 & 0 \\
\hline 3 & Agus Darsono & -1 & -1 & -1 \\
\hline 4 & Bias Fajar Baskoro & -1 & 0 & -1 \\
\hline 5 & Budi Kriswana & -1 & 0 & -1 \\
\hline 6 & Dedy Heryadi & -1 & -1 & -1 \\
\hline 7 & Devi Tresna Senjaya & 0 & -1 & -1 & \\
\hline
\end{tabular}




\begin{tabular}{|c|l|c|c|c|c|}
\hline \multirow{2}{*}{ No } & \multicolumn{2}{|c|}{ Nama } & \multicolumn{3}{|c|}{ Aspek Kerjasama } \\
\cline { 3 - 5 } & & K1 & K2 & K3 & \\
\hline 8 & Dian Eko & -1 & -1 & -1 \\
\hline 9 & Fatmawati & -1 & -1 & -1 \\
\hline 10 & H. Didih Suwardi & -1 & -1 & -1 & \\
\hline
\end{tabular}

b. Penentuan Bobot Nilai GAP

Setelah didapatkan tiap gap masing-masing guru maka tiap profil guru diberi bobot nilai dengan patokan tabel bobot nilai gap.

Tabel 7. Bobot Nilai GAP

\begin{tabular}{|c|c|c|l|}
\hline No & $\begin{array}{c}\text { Selisih } \\
\text { Nilai (GAP) }\end{array}$ & $\begin{array}{c}\text { Bobot } \\
\text { Nilai }\end{array}$ & \multicolumn{1}{|c|}{ Keterangan } \\
\hline 1 & 0 & 5 & $\begin{array}{l}\text { Tidak ada selisih (sesuai dengan yang } \\
\text { dibutuhkan) }\end{array}$ \\
\hline 2 & 1 & 4,5 & Kompetensi individu lebih 1 tingkat/ level \\
\hline 3 & -1 & 4 & Kompetensi individu kurang 1 tingkat/ level \\
\hline 4 & 2 & 3,5 & Kompetensi individu lebih 2 tingkat/ level \\
\hline 5 & -2 & 3 & Kompetensi individu kurang 2 tingkat/ level \\
\hline 6 & 3 & 2,5 & Kompetensi individu lebih 3 tingkat/ level \\
\hline 7 & -3 & 2 & Kompetensi individu kurang 3 tingkat/ level \\
\hline 8 & 4 & 1,5 & Kompetensi individu lebih 4 tingkat/ level \\
\hline 9 & -4 & 1 & Kompetensi individu kurang 4 tingkat/ level \\
\hline
\end{tabular}

Dengan demikian bobot nilai gap dari tiap alternatif dapat dilihat sebagai berikut:

Tabel 8. Hasil Bobot Nilai GAP Aspek Kedisiplinan

\begin{tabular}{|c|l|c|c|c|}
\hline \multirow{2}{*}{ No } & \multirow{2}{*}{ Nama } & \multicolumn{3}{c|}{ Aspek Kedisiplinan } \\
\cline { 3 - 5 } & & D1 & D2 & D3 \\
\hline 1 & Abdul Odih & 0 & 0 & 0 \\
\hline 2 & Adhimas Cahyo Kuncoro & 0 & 0 & -1 \\
\hline 3 & Agus Darsono & 0 & 0 & 0 \\
\hline 4 & Bias Fajar Baskoro & 0 & 0 & -1 \\
\hline 5 & Budi Kriswana & 0 & 0 & 0 \\
\hline 6 & Dedy Heryadi & 0 & -1 & 0 \\
\hline 7 & Devi Tresna Senjaya & 0 & 0 & -1 \\
\hline 8 & Dian Eko & -1 & -1 & 0 \\
\hline 9 & Fatmawati & 0 & 0 & -1 \\
\hline 10 & H. Didih Suwardi & 0 & 0 & 0 \\
\hline \multicolumn{2}{|l|}{ Nilai Bobot } & 5 & 5 & 5 \\
\hline 1 & Abdul Odih & 5 & 5 & 4 \\
\hline 2 & Adhimas Cahyo Kuncoro & 5 & 5 & 5 \\
\hline 3 & Agus Darsono & 5 & 5 & 4 \\
\hline 4 & Bias Fajar Baskoro & 5 & 5 & 5 \\
\hline 5 & Budi Kriswana & \multicolumn{2}{c}{} \\
\hline
\end{tabular}




\begin{tabular}{|c|l|c|c|c|}
\hline \multirow{2}{*}{ No } & \multicolumn{1}{|c|}{ Nama } & \multicolumn{3}{|c|}{ Aspek Kedisiplinan } \\
\cline { 3 - 5 } & & D1 & D2 & D3 \\
\hline 6 & Dedy Heryadi & 5 & 4 & 5 \\
\hline 7 & Devi Tresna Senjaya & 5 & 5 & 4 \\
\hline 8 & Dian Eko & 4 & 4 & 5 \\
\hline 9 & Fatmawati & 5 & 5 & 4 \\
\hline 10 & H. Didih Suwardi & 5 & 5 & 5 \\
\hline
\end{tabular}

Tabel 9. Hasil Bobot nilai GAP Aspek Kerjasama

\begin{tabular}{|c|l|c|c|c|}
\hline \multirow{2}{*}{ No } & \multicolumn{1}{|c|}{ Nama } & \multicolumn{3}{c|}{ Aspek Kerjasama } \\
\cline { 3 - 5 } & & K1 & K2 & K3 \\
\hline 1 & Abdul Odih & -1 & -1 & -1 \\
\hline 2 & Adhimas Cahyo Kuncoro & 0 & -1 & 0 \\
\hline 3 & Agus Darsono & -1 & -1 & -1 \\
\hline 4 & Bias Fajar Baskoro & -1 & 0 & -1 \\
\hline 5 & Budi Kriswana & -1 & 0 & -1 \\
\hline 6 & Dedy Heryadi & -1 & -1 & -1 \\
\hline 7 & Devi Tresna Senjaya & 0 & -1 & -1 \\
\hline 8 & Dian Eko & -1 & -1 & -1 \\
\hline 9 & Fatmawati & -1 & -1 & -1 \\
\hline 10 & H. Didih Suwardi & -1 & -1 & -1 \\
\hline & & 4 & 4 & 4 \\
\hline 1 & Abdul Odih & 5 & 4 & 5 \\
\hline 2 & Adhimas Cahyo Kuncoro & 4 & 4 & 4 \\
\hline 3 & Agus Darsono & 4 & 5 & 4 \\
\hline 4 & Bias Fajar Baskoro & 4 & 5 & 4 \\
\hline 5 & Budi Kriswana & 4 & 4 & 4 \\
\hline 6 & Dedy Heryadi & 5 & 4 & 4 \\
\hline 7 & Devi Tresna Senjaya & 4 & 4 & 4 \\
\hline 8 & Dian Eko & 4 & 4 & 4 \\
\hline 9 & Fatmawati & 4 & 4 & 4 \\
\hline 10 & H. Didih Suwardi & \multicolumn{2}{|c}{} \\
\hline
\end{tabular}

c. Menghitung nilai Rata-Rata Core Factor dan Nilai Rata Secondary Factor

Untuk perhitungan core factor dan secondary factor aspek kedisiplinan, dengan terlebih dahulu menentukan sub-aspek mana yang menjadi core factor dari aspek disiplin (sub aspek yaitu DS1 dan DS2), secondary factor dari aspek kedisiplinan (sub aspek yaitu DS3 dan DS4), kemudian nilau core factor dan secondary factor ini dijumlahkan sesuai rumus (1), (2) dan hasilnya dapat dilihat di tabel berikut: 
Tabel 10. Hasil Nilai Core Factor dan Secondary Factor Aspek Kedisiplinan

\begin{tabular}{|c|l|c|c|c|c|c|}
\hline \multirow{2}{*}{ No } & \multirow{2}{*}{ Nama } & \multicolumn{5}{|c|}{ Variabel } \\
\cline { 3 - 7 } & & D1 & D2 & D3 & CF & SF \\
\hline 1 & Abdul Odih & 5 & 5 & 5 & 5 & 5 \\
\hline 2 & Adhimas Cahyo Kuncoro & 5 & 5 & 4 & 5 & 4 \\
\hline 3 & Agus Darsono & 5 & 5 & 5 & 5 & 5 \\
\hline 4 & Bias Fajar Baskoro & 5 & 5 & 4 & 5 & 4 \\
\hline 5 & Budi Kriswana & 5 & 5 & 5 & 5 & 5 \\
\hline 6 & Dedy Heryadi & 5 & 4 & 5 & 4,5 & 5 \\
\hline 7 & Devi Tresna Senjaya & 5 & 5 & 4 & 5 & 4 \\
\hline 8 & Dian Eko & 4 & 4 & 5 & 4 & 5 \\
\hline 9 & Fatmawati & 5 & 5 & 4 & 5 & 4 \\
\hline 10 & H. Didih Suwardi & 5 & 5 & 5 & 5 & 5 \\
\hline
\end{tabular}

Tabel 11. Hasil Nilai Core Factor dan Secondary Factor Aspek Kerjasama

\begin{tabular}{|c|l|c|c|c|c|c|}
\hline \multirow{2}{*}{ No } & \multirow{2}{*}{ Nama } & \multicolumn{5}{|c|}{ Variabel } \\
\cline { 3 - 7 } & & K1 & K2 & K3 & CF & SF \\
\hline 1 & Abdul Odih & 4 & 4 & 4 & 4 & 4 \\
\hline 2 & Adhimas Cahyo Kuncoro & 5 & 4 & 5 & 4,5 & 5 \\
\hline 3 & Agus Darsono & 4 & 4 & 4 & 4 & 4 \\
\hline 4 & Bias Fajar Baskoro & 4 & 5 & 4 & 4,5 & 4 \\
\hline 5 & Budi Kriswana & 4 & 5 & 4 & 4,5 & 4 \\
\hline 6 & Dedy Heryadi & 4 & 4 & 4 & 4 & 4 \\
\hline 7 & Devi Tresna Senjaya & 5 & 4 & 4 & 4,5 & 4 \\
\hline 8 & Dian Eko & 4 & 4 & 4 & 4 & 4 \\
\hline 9 & Fatmawati & 4 & 4 & 4 & 4 & 4 \\
\hline 10 & H. Didih Suwardi & 4 & 4 & 4 & 4 & 4 \\
\hline
\end{tabular}

\section{d. Perhitungan Nilai Total}

Dari hasil perhitungan dari tiap aspek di atas kemudian dihitung nilai total berdasar presentasi dari core dan secondary yang diperkirakan berpengaruh terhadap kinerja tiap-tiap profil. Untuk lebih jelasnya penghitungan nilai total terlebih dahulu menentukan nilai persen yang diinputkan yaitu core factor $80 \%$ dan secondary factor $20 \%$. Kemudian nilai core factor dan secondary factor ini dijumlahkan sesuai rumus dan hasilnya dapat dilihat pada contoh perhitungan aspek kedisiplin dan aspek kerjasama.

Tabel 12. Hasil Nilai Total GAP Kedisiplinan

\begin{tabular}{|c|l|c|c|l|}
\hline No & \multicolumn{1}{|c|}{ Nama } & CF & SF & \multicolumn{1}{|c|}{ Nd } \\
\hline 1 & Abdul Odih & 5 & 5 & $(80 \% * 5)+(20 \% * 5)=5$ \\
\hline 2 & Adhimas Cahyo Kuncoro & 5 & 4 & $(80 \% * 5)+(20 \% * 4)=4,8$ \\
\hline 3 & Agus Darsono & 5 & 5 & $(80 \% * 5)+(20 \% * 5)=5$ \\
\hline 4 & Bias Fajar Baskoro & 5 & 4 & $(80 \% * 5)+(20 \% * 4)=4,8$ \\
\hline 5 & Budi Kriswana & 5 & 5 & $(80 \% * 5)+(20 \% * 5)=5$ \\
\hline 6 & Dedy Heryadi & 4,5 & 5 & $(80 \% * 4,5)+(20 \% * 5)=4,6$ \\
\hline 7 & Devi Tresna Senjaya & 5 & 4 & $(80 \% * 5)+(20 \% * 4)=4,8$ \\
\hline
\end{tabular}




\begin{tabular}{|c|l|c|c|l|}
\hline No & \multicolumn{1}{|c|}{ Nama } & CF & SF & \multicolumn{1}{c|}{ Nd } \\
\hline 8 & Dian Eko & 4 & 5 & $\left(80 \%{ }^{*} 4\right)+(20 \% * 5)=4,2$ \\
\hline 9 & Fatmawati & 5 & 4 & $(80 \% * 5)+(20 \% * 4)=4,8$ \\
\hline 10 & H. Didih Suwardi & 5 & 5 & $(80 \% * 5)+(20 \% * 5)=5$ \\
\hline
\end{tabular}

Tabel 13. Hasil Nilai Total GAP Kerjasama

\begin{tabular}{|c|c|c|c|c|}
\hline No & Nama & CF & SF & Nk \\
\hline 1 & Abdul Odih & 4 & 4 & $(80 \% * 4)+(20 \% * 5)=4$ \\
\hline 2 & Adhimas Cahyo Kuncoro & 4,5 & 5 & $(80 \% * 4,5)+(20 \% * 5)=4,6$ \\
\hline 3 & Agus Darsono & 4 & 4 & $(80 \% * 4)+(20 \% * 4)=4$ \\
\hline 4 & Bias Fajar Baskoro & 4,5 & 4 & $(80 \% * 4,5)+(20 \% * 4)=4,4$ \\
\hline 5 & Budi Kriswana & 4,5 & 4 & $(80 \% * 4,5)+(20 \% * 4)=4,4$ \\
\hline 6 & Dedy Heryadi & 4 & 4 & $(80 \% * 4)+(20 \% * 4)=4$ \\
\hline 7 & Devi Tresna Senjaya & 4,5 & 4 & $(80 \% * 4,5)+(20 \% * 4)=4,4$ \\
\hline 8 & Dian Eko & 4 & 4 & $(80 \% * 4)+(20 \% * 4)=4$ \\
\hline 9 & Fatmawati & 4 & 4 & $(80 \% * 4)+(20 \% * 4)=4$ \\
\hline 10 & H. Didih Suwardi & 4 & 4 & $(80 \% * 4)+(20 \% * 4)=4$ \\
\hline
\end{tabular}

e. Melakukan Perangkingan

Hasil akhir dari proses ini adalah rangking dari guru terbaik. Penentuan rangking mengacu pada hasil perhitungan tertentu. Perhitungan tersebut dapat ditunjukkan pada rumus di bawah ini:

$\mathrm{Ha}=(60) \% \mathrm{Nd}+(40) \% \mathrm{Nk}$

Keterangan:

Ha : Hasil akhir

$\mathrm{Nd} \quad$ : Nilai kedisiplinan

Ns : Nilai kerjasama

$(\mathrm{x}) \%$ : Nilai persen yang diinputkan

Berikut adalah tabel hasil akhir dan penentuan rangking guru terbaik berdasarkan metode profile matching:

Tabel 14. Hasil Akhir Berdasarkan Metode Profile Matching

\begin{tabular}{|c|l|c|c|l|}
\hline No & \multicolumn{1}{|c|}{ Nama } & Nd & Nk & \multicolumn{1}{c|}{ Score } \\
\hline 1 & Abdul Odih & 5 & 4 & $(60 \% * 5)+(40 \% * 4)=4,6$ \\
\hline 2 & Adhimas Cahyo Kuncoro & 4,8 & 4,6 & $(60 \% * 4,8)+(40 \% * 4,6)=4,72$ \\
\hline 3 & Agus Darsono & 5 & 4 & $(60 \% * 5)+(40 \% * 4)=4,6$ \\
\hline 4 & Bias Fajar Baskoro & 4,8 & 4,4 & $(60 \% * 4,8)+(40 \% * 4,4)=4,64$ \\
\hline 5 & Budi Kriswana & 5 & 4,4 & $(60 \% * 5)+(40 \% * 4,4)=4,76$ \\
\hline 6 & Dedy Heryadi & 4,6 & 4 & $(60 \% * 4,6)+(40 \% * 4)=4,36$ \\
\hline 7 & Devi Tresna Senjaya & 4,8 & 4,4 & $(60 \% * 4,8)+(40 \% * 4,4)=4,64$ \\
\hline 8 & Dian Eko & 4,2 & 4 & $(60 \% * 4,2)+(40 \% * 4)=4,12$ \\
\hline 9 & Fatmawati & 4,8 & 4 & $(60 \% * 4,8)+(40 \% * 4)=4,48$ \\
\hline 10 & H. Didih Suwardi & 5 & 4 & $(60 \% * 5)+(40 \% * 4)=4,6$ \\
\hline
\end{tabular}


Tabel I5. Hasil Rangking berdasarkan Metode Profile Matching

\begin{tabular}{|c|l|c|}
\hline No & \multicolumn{1}{|c|}{ Nama } & Rangking \\
\hline 1 & Muhamad Atib & $\mathbf{4 , 8}$ \\
\hline 2 & Budi Kriswana & 4,76 \\
\hline 3 & Irpan Sumartono & 4,76 \\
\hline 4 & Adhimas Cahyo Kuncoro & 4,72 \\
\hline 5 & Nana Permana & 4,68 \\
\hline 6 & Bias Fajar Baskoro & 4,64 \\
\hline 7 & Devi Tresna Senjaya & 4,64 \\
\hline 8 & Abdul Odih & 4,6 \\
\hline 9 & Agus Darsono & 4,6 \\
\hline 10 & H. Didih Suwardi & 4,6 \\
\hline
\end{tabular}

Dari hasil perhitungan menggunakan metode Profile Matching diatas dapat diketahui bahwa yang memiliki nilai terbesar dan menjadi guru terbaik yaitu Muhamad Atib.

\section{SIMPULAN}

a. Profile Matching memberikan alternatif keputusan dalam pengambilan keputusan menentukan guru terbaik pada SMK Madani Depok, berdasarkan tiap-tiap kriteria yang sudah ditentukan yaitu hadir tepat waktu, tanggung jawab, berpakaian rapih dan sopan, berpartisipasi dan berkontribusi, aktif dan produktif, dan membantu rekan guru.

b. Metode yang telah dilakukan perhitungan dapat menunjukan hasil peringkat pertama dari kriteria-kriteria yang telah ditentukan, yaitu Muhamad Atib. Jadi metode tersebut dapat diterapkan dan diimplementasikan pihak sekolah dalam pemilihan guru terbaik.

\section{DAFTAR PUSTAKA}

[1] Hutasoit, Rotua Sihombing, Agus Perdana Windarto, Dedy Hartama, dan Solikhun Solikhun. 2018. "Sistem Pendukung Keputusan Pemilihan Guru Terbaik Pada Smk Maria Goretti Pematangsiantar Menggunakan Metode Simple Additive Weighting (Saw)." Jurasik (Jurnal Riset Sistem Informasi dan Teknik Informatika) 1(1):56.

[2] Angeline, Mervin. 2018. "Sistem Pendukung Keputusan Pemilihan Karyawan Terbaik Menggunakan Metode Profile Matching." STMB Multismart II(2):45-51.

[3] Haryani dan Dina Fitriani. 2019. "Sistem Pendukung Keputusan Penentuan Karyawan Terbaik Pada Collection Pt . Panin Bank Menggunakan Metode Profile Matching." Jurnal Mantik Penusa 3(1):1-8.

[4] Hakim, Zainul, Aso Sudiarjo, dan Ririn Efrida. 2017. "Rancangan Sistem Penunjang Keputusan Pengangkatan Karyawan Tetap Dengan Metode Profile Matching di PT . Lotte Packaging." Sisfotek Global 7(2):13-19.

[5] Handayani, Irma. 2017. "Sistem Pendukung Keputusan Pemilihan Karyawan Berprestasi Dengan Metode Profile Matching Pada Pt. Sarana Inti Persada 
(SIP)." Jurnal Pilar Nusa Mandiri 13(1):28-34.

[6] Diana. 2018. Metode \& Aplikasi Sistem Pendukung Keputusan. Yogyakarta: Deepublish.

[7] Sari, R. D. I., \& Sindunata, Y. (2014). Penerapan Data Mining Untuk Analisa Pola Perilaku Nasabah Dalam Pengkreditan Menggunakan Metode C4.5 Studi Kasus Pada KSU Insan Kamil Demak. Jurnal Ilmiah Teknologi Dan Informasi ASIA, 8(2), $10-16$

[8] Dicky Nofriansyah; sarjon defit. 2017. Milti Criteria Decision Making (MCDM) Pada Sistem Pendukung Keputusan. Yogyakarta: Deepublish. 